\title{
Plural Three-Wave Resonant Interactions in the Transit Section of Two-Stream Superheterodyne FEL with a Longitudinal Electric Field
}

\author{
A.V. Lysenko*, I.I. Volk, G.A. Oleksiienko, M.A. Korovai, A.T. Shevchenko \\ Sumy State University, 2, Rymsky-Korsakov St., 40007 Sumy, Ukraine
}

(Received 10 June 2021; revised manuscript received 09 August 2021; published online 20 August 2021)

\begin{abstract}
In the present work, within the framework of nonlinear cubic approximation, the analysis of the possibility of controlling the parameters of a wide frequency spectrum in multiharmonic two-stream freeelectron lasers of klystron type by means of a longitudinal electric field was carried out. The quasihydrodynamic equation, the continuity equation and Maxwell equations were used as the calculation basis. Using the method of averaged characteristics, we obtained a system of differential equations describing the dynamics of wave harmonics amplitudes of a superheterodyne free-electron laser. We demonstrated that in the studied system, it was possible to realize plural three-wave parametric resonances between space charge wave harmonics. In this case, simultaneous three-wave resonant interaction between a number of triple harmonics of the space charge wave occurred. Such three-wave resonances were also interconnected through certain common harmonics. It was shown that the conditions of plural three-wave parametric resonances between space charge wave harmonics, which are amplified due to two-stream instability, persisted in a two-stream electron beam despite the change in the velocity of the two-stream electron beam under the influence of the longitudinal electric field. It was found that the longitudinal accelerating electric field led to a significant increase in the frequency spectrum width of the multiharmonic space charge wave. The decelerating electric field reduced the width of the frequency spectrum of this wave, but the level of harmonic saturation increased. We proposed to use the accelerating electric field in the transit section of the multiharmonic two-stream superheterodyne free-electron laser to generate powerful multiharmonic electromagnetic signals with a wide frequency spectrum, including ultrashort clusters.
\end{abstract}

Keywords: Superheterodyne free-electron laser, Two-stream instability, Three-wave parametric resonance, Space charge wave, Longitudinal electric field.

\section{INTRODUCTION}

Free-electron lasers (FELs) have a series of unique properties that attract the attention of researchers. Interest is primarily due to the ability to generate powerful coherent electromagnetic radiation in a continuous frequency range from millimeter wavelengths to Xrays [1-3]. Lately, intense research has been conducted on the FEL operation regimes, when ultrashort pulses formation occurs [1, 4-9]. Such FELs are able to create ultimately powerful ultrashort pulses, including femtosecond ones. Such pulses are today an indispensable tool for many applications, both in fundamental and applied research. We should also note the interest in systems capable of forming powerful electromagnetic signals with a broad frequency spectrum in the terahertz range [10, 11].

One of the ways to create ultrashort pulses is the method of wave packets compressing [1,7]. The essence of this method is the formation of an ultrashort pulse (cluster) as a result of superposition, overlapping of plurality of harmonics. In [1,7], the ability of a twostream superheterodyne FEL to form an ultrashort cluster of an electromagnetic field is demonstrated.

One of the TSFEL features is the use of two-stream instability as an additional amplification mechanism. Such instability has exceptionally high growth rates of the space charge wave (SCW) [1, 12], taking part in the three-wave parametric resonance in TSFEL. That is why such TSFELs are characterized by high amplification properties. We should also note that SCW growth due to the two-stream instability is characterized by a linear dispersion dependence [1, 7-9]. Due to this fact, the simultaneous realization of plurality of three-wave parametric resonances (plural resonances) between different harmonics of the growing SCW becomes possible. This leads to intense excitation of higher harmonics, which receive further amplification due to the twostream instability. As a result, the SCW with a broad frequency spectrum is formed, which acts as a source of multiharmonic waves in multiharmonic TSFEL.

The present paper is devoted to the study of mechanisms which allow to control the frequency spectra of waves formed by a multiharmonic TSFEL with straight two-stream relativistic electron beams (REBs). We investigate the effect of a longitudinal electrostatic field on the formation of the multiharmonic SCW. The uniqueness of the studied situation lies in the fact that a change in the longitudinal velocity of a two-stream REB under the influence of a longitudinal electrostatic field does not affect the conditions of three-wave parametric interactions between the SCW harmonics. This situation is ensured by the linearity of the dispersion characteristic of the growing SCW and by the synchronicity of changes in the dispersion properties of all SCW harmonics with a change in the REB velocity.

\section{MODEL}

We consider the operation principle of a multiharmonic two-stream superheterodyne klystron-type FEL. Its scheme is shown in Fig. 1. The two-stream electron beam 2 enters the modulation section 3 of the TSFEL amplifier. A transverse reversive H-ubitron

\footnotetext{
*lysenko_@ukr.net
} 
magnetic field is created in the modulation section. The monochromatic electromagnetic signal 1 with frequency $\omega_{1}$ and wavenumber $k_{1}$ is also supplied to the input of the modulation section. The multiharmonic SCW with frequency $\omega_{3,1}$ and wavenumber $k_{3,1}$ of the first harmonic is excited in the two-stream electron beam as a result of the three-wave parametric resonance between the signal wave 1 and the $\mathrm{H}$-ubitron magnetic field. Next, the electron beam 2, containing the excited SCW, enters the transit section 4 . Th electromagnetic signal wave 1 is absorbed in the transit section 4 .

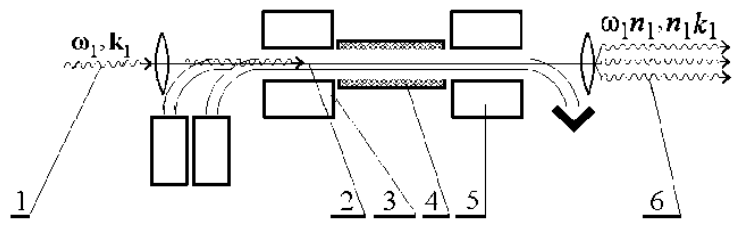

Fig. 1 - Scheme of a multiharmonic two-stream superheterodyne klystron-type FEL: 1 - monochromatic electromagnetic signal; 2 - electron beam; 3 - modulation section; 4 - transit section; 5 - terminal section; 6 - multiharmonic electromagnetic signal

Intensive excitation and amplification of higher harmonics due to the two-stream instability and multiple three-wave parametric resonances occur in the transit section 4 . The first SCW harmonic frequency $\omega_{3,1}$ is chosen to be much less than the critical frequency of the two-stream instability $\omega_{\text {cr }}$ for effective excitation of the SCW higher harmonics. Dispersion dependence of the SCW harmonics is linear [1, 7-9]. Thus, the frequency and wave number of any $m$-th harmonic of the SCW satisfy the relations:

$$
\omega_{3, m}=m \cdot \omega_{3,1}, k_{3, m}=m \cdot k_{3,1} .
$$

Therefore, $m_{1}, m_{2}$ and $m_{3}$ harmonics of the SCW must satisfy the conditions of the three-wave parametric resonance

$$
\omega_{3, m 1}=\omega_{3, m 2}+\omega_{3, m 3}, k_{3, m 1}=k_{3, m 2}+k_{3, m 3} .
$$

To do so, their numbers must be related by

$$
m_{1}=m_{2}+m_{3}
$$

A lot of harmonics meet this requirement. For example, the 6 -th harmonic takes part in a set of resonant interactions: $6=4+2,6=1+5$ and so on. Such resonant interactions are referred to as plural interactions [3,8]. Due to these interactions, many higher harmonics are generated in a two-stream electron beam.

It is known that the intensity of the parametric interaction decreases with increasing the SCW frequency. However, the SCW harmonics with frequencies less than the critical frequency of the two-stream instability are enhanced due to it. Consequently, the growth rate of the two-stream instability increases with frequency up to the two-stream instability optimal frequency $\omega_{\text {opt }}$ $[3,7]$. Thus, frequency of the first SCW harmonic $\omega_{\mathrm{cr}}$ is less than the optimal frequency $\omega_{\mathrm{opt}}$. Therefore, the growth rate of such harmonics increases with frequency due to the two-stream instability. As a result, a SCW with a wide frequency spectrum is formed. This spectrum has an abnormal part, in which harmonics with higher frequencies have higher amplitudes. Therefore, a SCW with a wide frequency spectrum is formed at the output of the transit section 4 .

In addition, a longitudinal constant electric field $\mathbf{E}_{0}$ is created in the transit section. This electric field can be both retarding and accelerating. In the current paper, the focus is on the effect of the electric field on the formation of multiharmonic SCWs. It is demonstrated that this field has a significant effect on the width of the multiharmonic SCW frequency spectrum, the saturation level and the length.

After leaving section 4 , the modulated beam enters the terminal section 5, where a multiharmonic $\mathrm{H}$-ubitron field is present. The system parameters are chosen in such a way that the conditions of parametric resonances between the triples of the $m$-th harmonics of the multiharmonic electromagnetic signal, pumping and SCW are met. The powerful multiharmonic electromagnetic signal 6 is generated and subsequently amplified due to such parametric resonances. Basically, the inverse transformation of the multiharmonic SCW energy into the energy of the multiharmonic electromagnetic signal occurs in the section 6 . The form of the SCW spectrum can be controlled in the transit section, e.g., by the longitudinal field. Hence, we can control the spectrum of the multiharmonic electromagnetic signal 6 , including the creation of an ultrashort electromagnetic field cluster [1].

\section{ANALYTICAL INVESTIGATION}

We use the quasi-hydrodynamic equation, the continuity equation, and Maxwell equations as the initial equations to analyze the processes in the described model. We apply the methods of the hierarchical theory of oscillations and waves to the initial equations. The electric field strength of the SCW is presented as

$$
\mathbf{E}_{3}=E_{3} \mathbf{e}_{z}=\sum_{m=1}^{N}\left[E_{3, m} \exp \left(i p_{3, m}\right)+c . c .\right] \mathbf{e}_{z},
$$

since it is formed as a multiharmonic wave in the transit section. Here, $E_{3, m}$ are the amplitudes of the $m$ th harmonics of the corresponding fields,

$$
p_{3, m}=\omega_{3, m} \cdot t-k_{3, m} \cdot z=m\left(\omega_{3,1} \cdot t-k_{3,1} \cdot z\right),
$$

are phases, $\mathbf{e}_{z}$ is the unit vector of the $Z$ axis, $N$ is the harmonic number that we account during the problem solving. We also consider that electrons of a two-stream beam move in a constant longitudinal electric field

$$
\mathbf{E}_{0}=E_{0} \mathbf{e}_{z} .
$$

Thus, the resulting electric field is $\mathbf{E}=\mathbf{E}_{0}+\mathbf{E}_{3}$. We consider that the collision and velocity spread of electrons can be neglected. In the current model, all quantities depend only on the longitudinal coordinate $z$ and 
time $t$. Thus, we can represent the relativistic quasihydrodynamic equation, the continuity equation, and Maxwell equations in the following form:

$$
\begin{gathered}
\left(\frac{\partial}{\partial t}+v_{\alpha z} \frac{\partial}{\partial z}\right) v_{\alpha z}=\frac{e E_{z}}{m_{e} \gamma_{\alpha}} \\
\left(\frac{\partial}{\partial t}+v_{\alpha z} \frac{\partial}{\partial z}\right) n_{\alpha}=-n_{\alpha} \frac{\partial v_{\alpha z}}{\partial z} \\
\frac{\partial E_{\mathrm{z}}}{\partial z}=4 \pi \sum_{\alpha=1}^{2} e n_{\alpha}
\end{gathered}
$$

where $v_{\alpha z}, \gamma_{\alpha}=\left(1-\left(v_{\alpha z} / c\right)^{2}\right)^{-1 / 2}$ are the velocity projection on the $Z$ axis and the relativistic factor of the $\alpha$-th electron beam, respectively, $c$ is the light speed, $e=-|e|$ and $m_{e}$ are the electron charge and mass, respectively, $n_{\alpha}$ is the electron density of the $\alpha$-th electron beam.

The process of solving the system of equations (7)(9) consists of three formally independent stages: solving the problem of the motion of a two-stream REB in given electromagnetic fields; solving the continuity equation assuming that electron beam velocities are known; solving the electromagnetic field excitation problem, assuming that the speed and concentration are known functions.

The problems of motion and continuity are solved using the averaged characteristics method [3], the electric field excitation problem is solved through the method of slowly varying amplitudes. In this case, we consider the features of plural three-wave parametric resonant interactions of the SCW and the signal wave. We make the transition from partial differential equations (7) and (8) to full differential equations (characteristics) in accordance with the method of averaged characteristics. Next, we use the hierarchical approach to the theory of oscillations and waves [3].

To solve the motion problem, we pass to the characteristic of equation (7) [3], which is a total differential equation. Since we are solving the boundary problem, we pass from the time derivative to the coordinate derivative using the general relation for the velocity $d t=d z / v_{z}$. We supplement the equation system with expressions for fast phases $p_{\alpha, m}$. The field amplitudes are considered as slowly varying with a change in the longitudinal coordinate $z$. In order to describe such slow variations of the amplitude, we introduce a slow longitudinal coordinate $\chi=z / \xi$. Here, $\xi$ is the problem large parameter defined by the ratio of the phase change rate to the wave amplitude change rate. As a result, we obtain the equation system represented in the standard way for the method of averaged characteristics [3]:

$$
\begin{gathered}
\frac{d v_{\alpha z}}{d z}=\frac{e}{m_{e} \gamma_{\alpha} v_{\alpha z}}\left(\sum_{m=1}^{N}\left[E_{3, m}(\chi) \exp \left(i p_{3, m}\right)+c . c .\right]+E_{0}\right), \\
\frac{d \chi}{d z}=\frac{1}{\xi}, \frac{d p_{3, \alpha, m}}{d z}=\frac{m \omega_{3,1}}{v_{\alpha z}}-k_{3, m} \equiv \Omega_{3, \alpha, m}
\end{gathered}
$$

We compare the system (10)-(11) with the standard one [3] and write the slow variables vector $\mathbf{x}$, vector- functions $\mathbf{X}$, the fast phase vector $\boldsymbol{\Psi}$ and the phase velocity vector $\boldsymbol{\Omega}$ in an explicit form

$$
\begin{gathered}
\mathbf{x}=\left\{x_{v_{\alpha z}}, x_{\chi}\right\}=\left\{v_{\alpha z}, \chi\right\}, \\
\frac{1}{\xi} \mathbf{X}=\left\{\frac{e}{m_{e} \gamma_{\alpha} v_{\alpha z}}\left(E_{3}+E_{0}\right), \frac{1}{\xi}\right\}, \\
\boldsymbol{\Psi}=\left\{p_{3, \alpha, 1}, \ldots, p_{3, \alpha, N}\right\}, \quad \boldsymbol{\Omega}=\left\{\Omega_{3, \alpha, 1}, \ldots, \Omega_{3, \alpha, N}\right\} .
\end{gathered}
$$

Next, we use the method of averaged characteristics [3] for the case of multiple fast phases. In accordance with its procedure, we pass to the averaged variables $\overline{\mathbf{x}}=\left\{\bar{v}_{\alpha z}, \bar{\chi}\right\}$ :

$$
\begin{gathered}
v_{\alpha z}=\bar{v}_{\alpha z}+\sum_{n=1}^{\infty} \frac{1}{\xi^{n}} u_{v_{\alpha z}}^{(n)}(\overline{\mathbf{x}}, \mathbf{\Psi}), \\
\chi=\bar{\chi}+\sum_{n=1}^{\infty} \frac{1}{\xi^{n}} u_{\chi}^{(n)}(\overline{\mathbf{x}}, \mathbf{\Psi}) .
\end{gathered}
$$

This substitution features the slow variables $\overline{\mathbf{x}}=\left\{\bar{v}_{\alpha z}, \bar{\chi}\right\}$ independent from the fast ones. They are defined by the relations

$$
\frac{d \bar{v}_{\alpha z}}{d z}=\sum_{n=1}^{\infty} \frac{1}{\xi^{n}} A_{v_{\alpha z}}^{(n)}(\overline{\mathbf{x}}), \frac{d \bar{\chi}}{d \mathrm{z}}=\sum_{n=1}^{\infty} \frac{1}{\xi^{n}} A_{\chi}^{(n)}(\overline{\mathbf{x}}) .
$$

We follow the procedure up to the third approximation by $1 / \xi$, i.e., $n=1,2,3$. The algorithm for finding $u^{(n)}$ and $A^{(n)}$ is known and described in e.g. [1]. As a result, we get solutions for both the oscillatory and constant components of the velocity. The solution for the concentration is derived similarly from the continuity equation.

The obtained solutions for the velocity and concentration as field functions are substituted into Maxwell equations. Thus, we obtain a system of self-consistent nonlinear differential equations for the complex amplitudes of the electric field strength harmonics of the increasing SCW in the cubic approximation

$$
\begin{gathered}
C_{2, m} \frac{d^{2} E_{3, m}}{d z^{2}}+C_{1, m} \frac{d E_{3, m}}{d z}+D_{m} E_{3, m}= \\
=C_{3, m}\left\langle E_{3} \cdot \sum_{m^{\prime}=1}^{N}\left[E_{3, m^{\prime}} \exp \left(\mathrm{i} p_{3, m^{\prime}}\right) /\left(\mathrm{i} m^{\prime}\right)+\text { c.c. }\right]\right\rangle_{p_{m}}+F_{m} .
\end{gathered}
$$

In equation (15),

$$
D_{m} \equiv-\mathrm{i} k_{3, m}\left(1-\sum_{\alpha=1}^{2} \frac{\omega_{\mathrm{p}, \alpha}^{2}}{\left(\omega_{3, m}-k_{3, m} \bar{v}_{\alpha z}\right)^{2} \bar{\gamma}_{\alpha}^{3}}\right)
$$

is the dispersion function of the SCW, $C_{2, m}=\partial^{2} D_{m} / \partial\left(-i k_{3, m}\right)^{2} / 2, C_{1, m}=\partial D_{m} / \partial\left(-i k_{3, m}\right), C_{3, m}=$ $=\sum_{\alpha=1}^{2} \frac{3 e \omega_{\mathrm{p}, \alpha}^{2} k_{3,1}}{\mathrm{i} m\left(\omega_{3,1}-k_{3,1} \bar{v}_{\alpha z}\right)^{3} v_{\alpha z} \bar{\gamma}_{\alpha}^{4} m_{e}}\left[\frac{\omega_{3,1}}{\left(\omega_{3,1}-k_{3,1} \bar{v}_{\alpha z}\right) \bar{\gamma}_{\alpha}^{2}}-1\right]$, $<\ldots>_{p_{3, m}}=\frac{1}{2 \pi} \int_{0}^{2 \pi}\left(\ldots \cdot \exp \left(-\mathrm{i} p_{3, m}\right)\right) d p_{3, m}, \quad F_{m}$ are func-

tions that account cubic nonlinear components and depend on the electric field strengths of the interacting waves harmonics. The coefficients of equation system 
(15) depend on the constant components of the velocities $v_{\alpha}$ and concentrations $n_{\alpha}$ of partial beams, which vary during the nonlinear interaction of the SCW harmonics. Therefore, we supplement system (15) with equations for constant components

$$
\begin{gathered}
\frac{d \bar{v}_{\alpha z}}{d z}=V_{\alpha}\left(E_{0}, E_{3,1}, \ldots, E_{3, N}, v_{\alpha}\right), \\
\frac{d \bar{n}_{\alpha}}{d z}=N_{\alpha}\left(E_{0}, E_{3,1}, \ldots, E_{3, N}, v_{\alpha}, \bar{n}_{\alpha}\right) .
\end{gathered}
$$

The system of equations (15), (17) allows to investigate the effect of the longitudinal constant electric field on the dynamics of the SCW in the transit section of the TSFEL within the framework of the cubicnonlinear approximation.

\section{DISCUSSION}

In this section, we analyze the effect of the longitudinal electric field on the SCW dynamics in the transit section of the TSFEL using the system of equations (15), (17). We consider the system with the following parameters: plasma frequency of each of the partial electron beams is $\omega_{\mathrm{p}}=1.0 \cdot 10^{11} \mathrm{~s}^{-1}$, average relativistic factor of the twostream beam is $\gamma_{0}=3.0$, partial electron beams relativistic factors difference is $\Delta \gamma=0.15$. We consider $N=50$ harmonics in the calculations. We discuss the case when only one SCW harmonic is excited at the entrance to the transit section ( $z=0$ ). The first SCW harmonic frequency is taken $\omega_{3,1}=5.8 \cdot 10^{11} \mathrm{~s}^{-1}$, which is 15 times less than the two-stream instability critical frequency $\omega_{\text {cr }}=8.7 \cdot 10^{12} \mathrm{~s}^{-1}$.

Therefore, as described above, the excitation and amplification of higher harmonics occurs in a twostream electron beam due to parametric resonant interactions. These processes involve harmonics whose frequencies are less than the two-stream instability critical frequency. These harmonics are also amplified due to the two-stream instability effect. The resulting amplification of harmonics is defined by the two-stream instability growth rates, since they are much higher than the three-wave parametric resonance growth rates. One should expect that the spectrum of harmonics (or the dependence of the harmonic amplitude on frequency at some coordinate $z$ ) is defined by the dependence of the growth rate on frequency. An approximate analytical solution for the maximum growth rate $\Gamma\left(\omega_{\mathrm{opt}}\right)$ and critical frequency $\omega_{\mathrm{cr}}$ can be simply derived from the dispersion equation (16) $[1,8]$ :

$$
\begin{gathered}
\Gamma\left(\omega_{\mathrm{opt}}\right)=\frac{\omega_{\mathrm{p}}}{2 v_{0} \gamma_{0}^{3 / 2}}, \\
\omega_{\mathrm{cr}}=\frac{2 \sqrt{2} \cdot \omega_{\mathrm{p}} \gamma_{0}^{3 / 2}\left(1-1 / \gamma_{0}^{2}\right)}{\Delta \gamma},
\end{gathered}
$$

where $v_{0}$ is the average velocity of the two-stream electron beam.

We analyze the effect of the longitudinal electric field $E_{0}$ on the maximum growth rate $\Gamma\left(\omega_{\text {opt }}\right)$ (18) and critical frequency $\omega_{\mathrm{cr}}$ (19). First, the influence of the field $E_{0}$ leads to a change in the average relativistic factor $\gamma_{0}$. In case of the accelerating field $E_{0}$ the relativistic factor $\gamma_{0}$ increases and in case of the retarding field $E_{0}$ the relativistic factor $\gamma_{0}$ decreases. The average velocity of the two-stream electron beam is close to the speed of light and changes slightly with the relativistic factor $\gamma_{0}$ change. Other parameters included in relations (18) and (19) remain almost unchanged. It means that in case of the accelerating electric field $E_{0}$, the growth rate decreases and the critical frequency increases. If the electric field $E_{0}$ is retarding, then, on the contrary, the growth rate increases, and the critical frequency decreases.

We obtain the same result from the equation system (15)-(17), which describes the amplitude dynamics of the SCW harmonics in the cubic nonlinear approximation. Fig. 2, Fig. 3, Fig. 4 show the SCW spectra in the investigated system in the saturation region for cases without the longitudinal electric field $E_{0}$, with the accelerating longitudinal field $E_{0}$ and with the decelerating field $E_{0}$, respectively. The longitudinal electric field strength is $E_{0}=3,0 \cdot 10^{5} \mathrm{~V} / \mathrm{m}$. The spectra in Fig. 2, Fig. 3, Fig. 4 are achieved at the coordinate $z$ close to the saturation region.

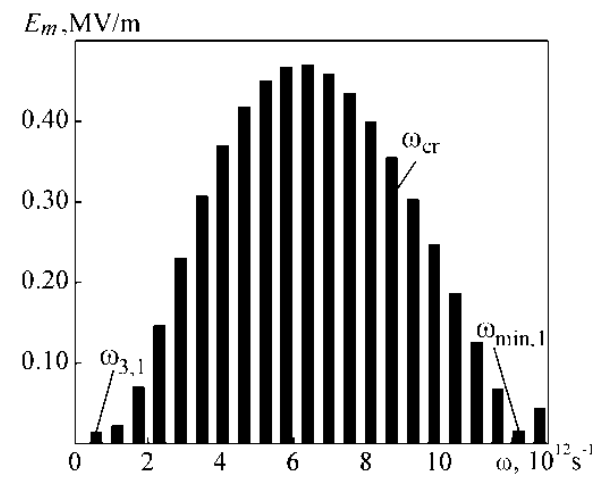

Fig. 2-SCW harmonic amplitudes $E_{m}$ dependence on the frequency $\omega$ for two-stream REB at $z_{1}=110 \mathrm{~cm}$, accelerating longitudinal electric field is absent

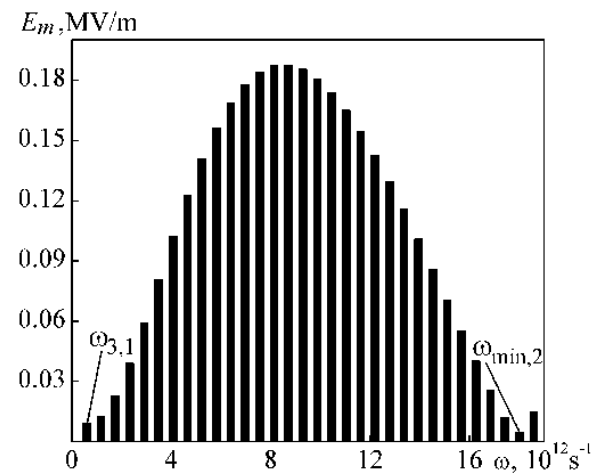

Fig. 3 - SCW harmonic amplitudes $E_{m}$ dependence on the frequency $\omega$ for two-stream REB at $z_{2}=166 \mathrm{~cm}$, accelerating longitudinal electric field is $E_{0}=3.0 \cdot 10^{5} \mathrm{~V} / \mathrm{m}$

It follows from Fig. 2, Fig. 3, Fig. 4 that the multiharmonic SCW with a wide frequency spectrum is formed in all three cases. Thus, if the field is absent 
(Fig. 2), the SCW spectrum width is $\omega_{\min , 1}-\omega_{3,1}=1.2 \cdot 10^{13} \mathrm{~s}^{-1}(20$ harmonics $)$ and saturation occurs in the vicinity of $z_{1}=110 \mathrm{~cm}$. This spectrum has an abnormal part: the first 11 harmonics whose amplitudes increase with frequency.

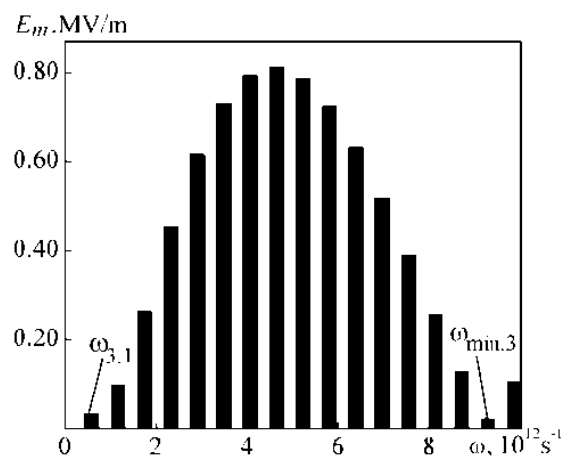

Fig. 4-SCW harmonic amplitudes $E_{m}$ dependence on the frequency $\omega$ for two-stream REB at $z_{3}=84 \mathrm{~cm}$, retarding longitudinal electric field is $E_{0}=3.0 \cdot 10^{5} \mathrm{~V} / \mathrm{m}$

Fig. 3 demonstrates a change in the SCW spectrum under the accelerating longitudinal electric field $E_{0}$ influence. One can see that the multiharmonic SCW spectrum width $\omega_{\min , 2}-\omega_{3,1}=1.75 \cdot 10^{13} \mathrm{~s}^{-1} \quad(30$ harmonics) increases by 1.5 times compared with the case when the field $E_{0}$ is absent (Fig. 2). At the same time, an increase in the saturation length by a factor of 1.5 occurs, and saturation is reached in the vicinity of $z_{2}=166 \mathrm{~cm}$. It should also be noted that the maximum amplitude of the multiharmonic signal decreases approximately by 2 times. Thus, the accelerating electric field allows to sufficiently increase the width of the multiharmonic SCW spectrum, although at the same time, the harmonic amplitudes decrease, and the saturation length increases. Such kind of field should be used in multiharmonic FELs with the main purpose of electromagnetic waves with the formation of the maximum width of the frequency spectrum.

Fig. 4 demonstrates a change in the SCW spectrum under the retarding longitudinal electric field $E_{0}$ influence. The multiharmonic SCW spectrum width

\section{REFERENCES}

1. V. V. Kulish, Hierarchic Electrodynamics and Free Electron Lasers: Concepts, Calculations, and Practical Applications (CRC Press, 2011).

2. C. Feng, H.-X. Deng, Nucl. Sci. Tech. 29 No 11, 160 (2018).

3. E.A. Seddon, J.A. Clarke, D.J. Dunning et al., Rep. Prog. Phys. 80 No 11, 115901 (2017).

4. W. Kaiser, Ultrashort Laser Pulses and Applications (Springer Science \& Business Media, 2013).

5. P.K. Maroju, C. Grazioli, M. Di Fraia et al., Nature 578 No 7795,386 (2020).

6. R. Kiessling, W.B. Colson, S. Gewinner, et al., Phys. Rev. Accel. Beams 21 No 8, 080702 (2018).

7. V.V. Kulish, A.V. Lysenko, V.V. Koval, M.Yu. Rombovsky, $\omega_{\min , 3}-\omega_{3,1}=0.87 \cdot 10^{13} \mathrm{~s}^{-1}$ (15 harmonics) decreases

by 1.4 times compared with the case when the field $E_{0}$ is absent (Fig. 2). At the same time, a decrease in the saturation length by a factor of 1.3 occurs, and saturation is reached in the vicinity of $z_{3}=84 \mathrm{~cm}$. One should also note that the maximum amplitude of the multiharmonic signal increases approximately by 2 times. Therefore, the retarding electric field $E_{0}$ allows to increase the SCW harmonics amplitude sufficiently and decrease the saturation length. This allows to achieve smaller longitudinal dimensions of the system. At that, the frequency spectrum width decreases. This kind of field should be applied in TSFELs intended to form electromagnetic waves with maximum amplitude.

\section{CONCLUSIONS}

We analyzed the effect of a longitudinal constant electric field on the SCW dynamics in the transit section of a TSFEL in the framework of the cubic nonlinear approximation. We demonstrated that the retarding electric field increases the saturation level and decreases the width of the frequency spectrum of the multiharmonic SCW in the transit section of the TSFEL. Also, the saturation length decreases, which leads to a decrease in the longitudinal dimensions of the investigated device. We proposed to use the retarding electric field in TSFELs operating in the maximum amplification mode, since this kind of field allows to obtain powerful electromagnetic waves with greater amplitudes and an improved degree of monochromaticity. It was also found that the accelerating longitudinal electric field increases the frequency spectrum width of the multiharmonic SCW. In this case, the saturation level of the SCW decreases and the saturation length increases. Therefore, the accelerating longitudinal electric field should be applied in multiharmonic TSFELs, which are used to generate an electromagnetic signal with a wide frequency spectrum. It should be assumed that effects associated with the retarding and accelerating longitudinal electric fields in the transit section of the klystron-type TSFELs can also occur in single-section TSFEL models.

I.I. Volk, Acta Physica Polonica A 131 No 2, 213 (2017).

8. A. Lysenko, M. Rombovsky, V. Koval, Iu. Volk, Chin. Phys. B 24 No 9, 095201 (2015)

9. V.V. Kulish, A.V. Lysenko, G.A. Oleksiienko, V.V. Koval, M.Y. Rombovsky, Acta Physica Polonica A 126, 1263 (2014).

10. G. Liao, Y. Li, IEEE Trans. Plasma Sci. 47 No 6, 3002 (2019).

11. S. Banerjee, B.P. Pal, D.R. Chowdhury, J. Electromagnetic Wave. Appl. 34 No 10, 1314 (2020).

12. R.J. Goldston, Introduction to Plasma Physics (CRC Press: 2020). 


\title{
Множинні трихвильові резонансні взаємодії в пролітній секції двопотокового супергетеродинного ЛВЕ з поздовжнім електричним полем
}

\author{
О.В. Лисенко, Ю.Ю. Волк, Г.А. Олексієнко, М.О. Коровай, А.Т. Шевченко
}

Сулський державний університет, вул. Римського-Корсакова, 2, 40007 Сули, Украйна

У поданій роботі в рамках нелінійного кубічного наближення проведено аналіз можливості керування параметрами широкого частотного спектра у мультигармонічних двопотокових лазерах на вільних електронах клістронного типу за допомогою поздовжнього електричного поля. Як базові використано квазігідродинамічне рівняння, рівняння неперервності та рівняння Максвела. За допомогою методу усереднених характеристик отримано систему диференціальних рівнянь, які описують дина міку амплітуд гармонік хвиль супергетеродинного лазера на вільних електронах. З'ясовано, що в досліджуваній системі можлива реалізація множинних трихвильових параметричних резонансів між гармоніками хвилі просторового заряду. У цьому разі має місце одночасна трихвильова резонансна взаемодія між багатьма трійками гармонік хвилі просторового заряду. Такі трихвильові резонанси до того ж пов'язані між собою через певні загальні гармоніки. Продемонстровано, що умови множинних трихвильових параметричних резонансів між гармоніками хвилі просторового заряду, які зростають через двопотокову нестійкість, в двопотоковому електронному пучку зберігаються, незважаючи на зміну швидкості двопотокового електронного пучка під впливом поздовжнього електричного поля. З'ясовано, що поздовжне прискорювальне електричне поле призводить до значного збільшення ширини частотного спектра мультигармонічної хвилі просторового заряду. Уповільнююче електричне поле призводить до зменшення ширини спектру частоти ціеї хвилі, але рівень насичення гармонік збільшуеться. Запропоновано використовувати прискорювальне електричне поле в пролітній секції мультигармонічного двопотокового супергетеродинного лазера на вільних електронах для формування потужних мультигармонічних електромагнітних сигналів із широким частотним спектром, включаючи ультракороткі кластери.

Ключові слова: Супергетеродинний лазер на вільних електронах, Двопотокова нестійкість, Трихвильовий параметричний резонанс, Хвилі просторового заряду, Повздовжне електричне поле. 